Lysenko, O. (1958). J. gen. Microbiol. 18, 774-781

\title{
'Streptococcus bombycis', its Taxonomy and Patho- genicity for Silkworm Caterpillars
}

\author{
By O. LYSENKO \\ Czechoslovak Academy of Science, Institute of Biology, Laboratory of Insect \\ Pathology, Prague, Czechoslovakia
}

SUMMARY: It was found that the streptococci known as Streptococcus bombycis have affinities with Streptococcus faecalis and S. faecium. S. bombycis is not a welldefined species and its entity is doubtful; it is proposed, therefore, that the name $S$. bombycis and its synonyms, which are given, be rejected. These streptococci are pathogenic for the silkworm, causing a disease of the gut. The mechanism of the pathogenicity is discussed.

The streptococcal diseases of the silkworm, Bombyx mori L., have been known for a long time, but neither their origin nor their aetiology has been satisfactorily explained. In the past 'Streptococcus bombycis' was designated as a cause of 'gattine' (schindsucht, macilenza), but later this disease was found to be of virus origin, and streptococci were only secondary invaders. A summary of these views was given by Steinhaus (1949). A precise determination of $S$. bombycis has not been made and the taxonomy of the organism is doubtful. It is not known who first used the name, which is thus connected with various authors. Pasteur when investigating 'ferment au chapeletes de grains', considered the bacterium to cause 'flacherie' and from this investigation the designation Streptococcus bombycis (Pasteur) Flügge 1886 has its origin. Streptococcus bombycis Zopf 1884 and Streptococcus bombycis Sartirana \& Paccanaro 1906 have also been described. The synonymy is confused and not fully known: Bergey's Manual (1948) quotes (p. 254) Streptococcus bombycis as one of the synonyms for Micrococcus bombycis (Naegeli) Cohn, but a protozoon, Nosema bombycis Naegeli, is meant. In another place (p. 337) in Bergey's Manual it is stated that Streptococcus bombycis Sartirana \& Paccanaro is not a synonym for Streptococcus bombycis Zopf. Paillot (1928) considered Streptococcus bombycis Sartirana \& Paccanaro and Streptococcus pastorianus Krassilstschik 1896 to be identical; but this view was not shared by Krassilnikov (1949). In addition, the name Diplococcus bombycis Paillot, 1922, may be found in the literature, but some workers consider it also to be a streptococcus (Steinhaus, 1949). From this review it is clear that taxonomically and nomenclaturally the position of organisms named Streptococcus bombycis is doubtful. The difficulty is that the original description and the original cultures are lost and the descriptions which are available contain only general features so that a correct determination is impossible. All descriptions of Streptococcus bombycis agree that it is Gram-positive, and the cocci, 0.7-0.9 $\mu$. in size, are arranged in short or long chains. The micro-organism grows well on ordinary 
solid media and forms small colonies; gelatin is not liquefied and litmus milk is acidified. The recent description by Masera (1954) does not add any useful information. Seelemann (1942) was the first to try to determine strains of $S$. bombycis by methods used for streptococci and stated that $S$. bombycis belonged to the group of enterococci with features similar to $S$. faecium. Seeleman's taxonomy of enterococci differs from more recent schemes of this group of bacteria; in his manual of streptococci (Seelemann, 1948) we find $\boldsymbol{S}$. faecium as one species and $\boldsymbol{S}$. glycerinaceus, as a synonym of $\boldsymbol{S}$. faecalis, as another. In recent taxonomic studies of enterococci (Shattock, 1955; Lake, Deibel \& Niven, 1957) a number of differences between $S$. faecalis and $S$. faecium are given, but these do not invalidate Seelemann's determination. Seelemann was the first to determine $S$. bombycis with approximate accuracy, a fact to be recognized by all workers in insect pathology. In this paper I discuss the taxonomic position of organisms named Streptococcus bombycis, using biochemical features and infection experiments on silkworms.

\section{METHODS}

Strains of streptococci were isolated from epizootics in populations of silkworms; the characters of these strains resembled those described for Streptococcus bombycis. To my strains were added strains isolated from healthy silkworms, and, for comparison, one strain each of $S$. faecalis and $S$. faecium. The

Table 1. Source and designation of strains of streptococci examined

\begin{tabular}{|c|c|c|c|}
\hline Designation & Source of isolation & $\begin{array}{c}\text { Year of } \\
\text { isolation }\end{array}$ & $\begin{array}{c}\text { No. of strains } \\
\text { isolated }\end{array}$ \\
\hline Bm $1 \mathbf{M}$ & $\begin{array}{l}\text { Bombyx mori, gattine, dead } \\
\text { silkworms, Czechoslovakia }\end{array}$ & 1956 & 2 \\
\hline Bm 3M & $\begin{array}{l}\text { B. mori, gattine, sick silkworms, } \\
\text { Czechoslovakia }\end{array}$ & 1956 & 1 \\
\hline Bm J 1 & $\begin{array}{l}\text { B. mori, dead silkworms, } \\
\text { Yugoslavia }\end{array}$ & 1956 & $\mathbf{1}$ \\
\hline $\operatorname{Bm~B~1(*)~}$ & $\begin{array}{l}\text { B. mori, dead silkworms, } \\
\text { Czechoslovakia }\end{array}$ & 1956 & $\mathbf{1}$ \\
\hline Sc 3 & $\begin{array}{l}\text { B. mori, dead silkworms, } \\
\text { Czechoslovakia }\end{array}$ & 1957 & 4 \\
\hline Sc 2 & $\begin{array}{l}\text { B. mori, healthy silkworms, } \\
\text { Czechoslovakia }\end{array}$ & 1957 & 5 \\
\hline
\end{tabular}

Streptococcus faecium NCTC $6783(\dagger)$

Streptococcus faecalis $\mathbf{S} 197$, isolated from a fly Protophormia terraenovae, Czechoslovakia, $195 \%$.

* This strain was isolated by Dr Vankova.

+ This strain was received as $\boldsymbol{S}$. faecalis, but it was found that its biochemical features are the same as those given by Shattock (1955) and by Lake et al. (1957) for $S$. faecium.

designations of strains and their sources are given in Table 1. The methods used were those given in Seelemann's monograph (1948) and in papers by Shattock \& Hirsch (1947), Skadhauge (1956), Shattock (1955), Barnes (1956) 
and Lake et al. (1957) in which more modern methods for distinguishing enterococci are given.

The examination of pathogenicity of our strains was made on healthy silkworms, kept at laboratory temperature and fed with fresh washed mulberry leaves. For each experiment 25-50 silkworms were used. The infectivity of the streptococcal strains Bm $1 \mathrm{M}, \mathrm{Bm} 3 \mathrm{M}, \mathrm{Bm} \mathrm{J} 1$, of Streptococcus faecium and of $S$. faecalis was tested by feeding the organisms to silkworms. Strain Bm $1 \mathbf{M}$ was also examined by injection into the body cavity of silkworms. Strains were preserved at $4^{\circ}$ on agar slopes under medicinal paraffin oil.

The methods of infection were those used in earlier work (Weiser \& Lysenko, 1956) with the difference that, instead of a glass capillary, a tuberculin syringe with fine intradermal needle was used to inject the body cavity of silkworms with $0.02 \mathrm{ml}$. of a suspension of streptococci (one loopful of $24 \mathrm{hr}$. culture from Tryptose agar suspended in $10 \mathrm{ml} .0 \cdot 6 \%$, w/v, NaCl solution). Feeding experiments were made in the following way: silkworms of the third and fourth stage were fed with leaves infected with a heavy suspension of a streptococcal culture, the infected food being served only once to animals starved for one day.

In dead silkworms the presence of streptococci was proved by microscopical examination and by culture on blood agar. A short examination of physiological features of colonies resembling streptococci was made by the following tests: growth in the presence of $6.5(\mathrm{w} / \mathrm{v}) \mathrm{NaCl}$; growth at pH 9.6; growth in the presence of potassium tellurite $1 / 2500$; reduction of litmus milk; growth at $45^{\circ}$; fermentation of arabinose (for details of tests see literature cited). The localization of streptococci in the bodies of silkworms was examined on histological sections stained by Gram's method and counterstained with eosin Y $0.1 \%(w / v)$ aqueous solution.

\section{RESULTS}

All the strains examined were typical enterococci by their biochemical and morphological features, the common features of our bombyx strains being as follows : good growth at $45^{\circ}$, and at $\mathrm{pH} 9 \cdot 6$; resisted heating at $60^{\circ}$ for $30 \mathrm{~min}$. These strains fermented glucose, mannitol, sucrose; gelatin was not liquefied. The strains were able to grow in the presence of $40 \%(\mathrm{w} / \mathrm{v})$ bile. They were not pathogenic for white mice on intraperitoneal injection. Other features, in which the bombyx strains differed from one another are given in Table 2. which also gives the features of bombyx strains reported by Seelemann (1942).

There were some features of the bombyx strains which were common with those of Streptococcus faecalis (inability to ferment arabinose) and on the other hand with those of $S$. faecium (glycerol not fermented anaerobically; citrates not used). The biochemical characters in which the bombyx strains differed from one another were:

(i) The reaction on blood agar was variable, some strains produced weak haemolysis, others showed all the variations between slight greening to classical $\alpha$-haemolysis and others were frankly non-haemolytic. 
(ii) Growth in the presence of $6.5 \%(\mathrm{w} / \mathrm{v}) \mathrm{NaCl}$ was weak or nil; this was found also by Seelemann (1942).

(iii) Reduction of litmus milk: variable and not persistent; the maximum degree of reduction, if it appeared, might be observed after the incubation for $16 \mathrm{hr}$. but as a rule colour returned after two days.

(iv) Sorbitol was fermented slowly by most strains.

(v) Reduction of triphenyltetrazolium chloride: weak (pink colonies after 3 days) or negative.

(vi) Ability to grow in potassium tellurite 1/2500: weak (a small black sediment at bottom of test-tube) or absent.

On the basis of these observations it is clear that the bombyx strains examined were an ill-defined group of forms having affinities with Streptococcus faecalis and $S$. faecium. Differences were not found as between the bombyx strains isolated from sick or healthy silkworms.

\section{Table 2. Biochemical characters of bombyx strains examined}

All the bombyx strains studied here had the following characters: good growth at $45^{\circ}$, and at pH 9.6; resistant to $60^{\circ}$ for $30 \mathrm{~min}$.; glucose, mannitol, sucrose fermented; gelatin not liquefied; growth in presence of $40 \%(w / v)$ bile.

\begin{tabular}{|c|c|c|c|c|c|c|c|}
\hline \multirow[b]{2}{*}{$\begin{array}{l}\text { Blood agar, greening to } \\
\alpha \text {-haemolysis }\end{array}$} & \multicolumn{7}{|c|}{ Bombyx strains } \\
\hline & $\begin{array}{c}\mathbf{B m} \mathbf{1} \mathbf{M} \\
(+)\end{array}$ & $\begin{array}{c}\mathrm{Bm} \mathbf{3} \mathbf{M} \\
(+)\end{array}$ & $\underset{-}{\mathrm{Bm} \mathbf{J} 1}$ & $\begin{array}{c}\mathrm{Bm} \text { B } 1 \\
-\end{array}$ & $\begin{array}{l}\text { Sc } 3 \\
(+)\end{array}$ & $\begin{array}{l}\text { Sc } 2 \\
(+)\end{array}$ & $\begin{array}{l}\text { Seel.* } \\
+\end{array}$ \\
\hline $\begin{array}{l}\text { Growth with NaCl 6.5 \% } \\
\text { Reduction of litmus milk }\end{array}$ & $\begin{array}{l}(+) 5 \\
(+)\end{array}$ & $\stackrel{+}{(+)}$ & $\begin{array}{c}(+) \\
+\end{array}$ & $\stackrel{+}{(+)}$ & $\begin{array}{c}(+) \\
+\end{array}$ & $\bar{t}$ & $\overline{(+)}$ \\
\hline $\begin{array}{l}\text { Acid from glycerol } \\
\text { anaerobically }\end{array}$ & - & - & - & - & - & - & n.t. \\
\hline Sorbitol & +5 & +5 & +5 & +2 & +5 & +2 & n.t. \\
\hline Arabinose & - & - & - & - & - & - & n.t. \\
\hline Utilization of citrates & - & - & - & - & - & - & n.t. \\
\hline Potassium tellurite $1 / 2500$ & $(+)$ & - & - & $(+)$ & $(+) 3$ & $(+)$ & n.t. \\
\hline Tetrazolium reduction & $(+) 3$ & $(+) \mathbf{3}$ & $(+) 3$ & $(+) 3$ & + & $(+)$ & n.t. \\
\hline
\end{tabular}

$+=$ Positive reaction; $(+)=$ weakly positive; $-=$ negative reaction; (the number beside the sign indicates the day on which reaction was observed); n.t.=not tested. Seel*= features of Seelemann's bombyx strains.

The results of infection experiments are given in Figs. 1 and 2. Figure 1 shows the mortality caused by feeding strains $\mathrm{Bm} 1 \mathrm{M}, \mathrm{Bm} 3 \mathrm{M}$ and $\mathrm{Bm} \mathrm{J1}$, Streptococcus faecalis or $\boldsymbol{S}$. faecium. Figure 2 gives curves indicating the mortality of silkworms after feeding and parenteral inoculation of strain $\mathrm{Bm} \mathbf{1}$ M. For comparison are given the results obtained by similar experiments with this strain made soon after its isolation in 1956, and those made after its preservation in the laboratory for a year. In PI. 1, fig. 1, the typical diplococcal arrangement of streptococci in the gut of an infected silkworm is shown; Plate 1, fig. 2, shows a section of haemolymph of a dead silkworm containing streptococci and other bacteria, and the localization of streptococci in the gut $(G)$ of a silkworm is shown in Pl. 1, fig. 3.

Thus, as may be seen, the streptococci were pathogenic for silkworms and the pathogenicity of bombyx strains was to some extent greater than that of 
the strains of Streptococcus faecalis and S. faecium used (Fig. 1). Infection by injection was more severe than the infection by feeding. After an incubation period of about 3 days the disease became apparent in injected silkworms and they began to die; within 7 days the mortality reached $100 \%$. With infection by feeding the incubation period was the same as by injection, but the disease then had a chronic character, and the mortality never reached $100 \%$; some silkworms survived the infection.

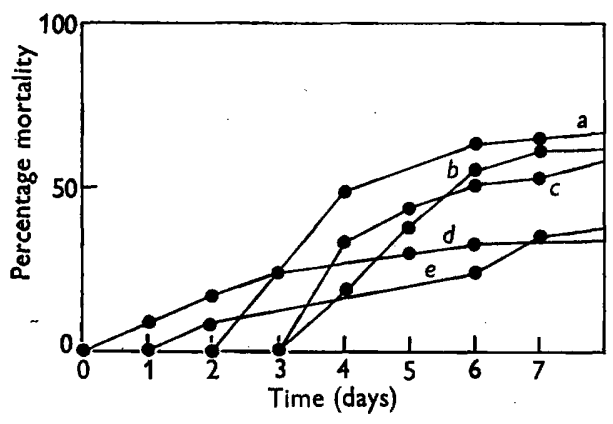

Fig. 1

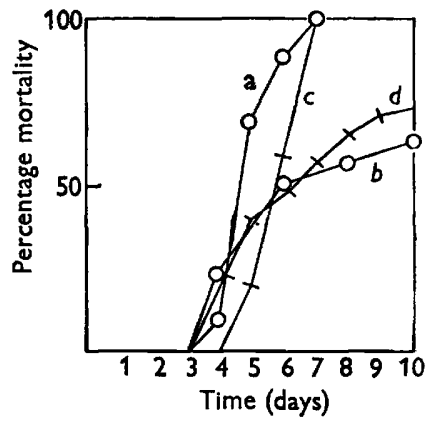

Fig. 2

Fig. 1. Death of silkworms after feeding strains: $a=$ strain $\mathrm{Bm} \mathbf{J} 1 ; b=\operatorname{strain} \mathrm{Bm} 3 \mathbf{M}$; $c=$ strain $\mathrm{Bm} 1 \mathrm{M} ; d=$ Streptococcus faecium; $e=S$. faecalis. Control deaths $=0$.

Fig. 2. Death of silkworms after the infection by the strains $\mathrm{Bm} 1 \mathrm{M}$. (a) by injection in the year 1957; (b) by feeding in the year 1956; (c) by injection in the year 1956 ; (d) by feeding in the year 1956. Mortality in controls in all experiments 5-10\% (not shown).

It is remarkable that the incubation period was similar by both routes of infection; according to my experience this is unusual with other microorganisms. I came to the conclusion that the streptococci did not cause a septicaemia but that the sickness was of gut origin. This I proved by histological examination; the streptococci were observed only in the gut and never in the body cavity or in the tissues of silkworms. Streptococci were found also in the haemolymph post mortem but they were there accompanied by other bacteria, especially pseudomonads, enterobacteria and staphylococci. My results are similar to those of Paillot $(1930 a, b$,$) . It is also to be noted that$ for infection by feeding, large doses of infectious material must be used. It is also interesting that the virulence of the strain $\mathrm{Bm} 1 \mathrm{M}$ was not changed by its preservation under oil for a year.

\section{DISCUSSION}

From the experiments reported it can be stated that the bacteria isolated from the epizootics and designated Streptococcus bombycis were a heterogeneous group of streptococci; it was impossible to allocate them to the species $S$. faecalis or to $S$. faecium, with which they have affinities. On the other hand these strains could not be made into an independent species (bombycis) of the enterococcus group, because they showed great heterogeneity of biochemical features. According to Sneath (1957) such intermediate strains should be 
regarded as inter-forms and a separate term 'gephyron' was proposed for this purpose.

Michailov (1950) examined 298 strains of Streptococcus bombycis, which he considered to belong to the group of lactic streptococci, and concluded that these strains differed from one another in the action of litmus milk, on blood agar, in fermentation of mannitol and in temperature for optimal growth. Masera's (1954) strain of $S$. bombycis liquefied gelatin on prolonged incubation. These reports demonstrate the great variability of biochemical characters of strains named Streptococcus bombycis and may partly explain the differences which occur between various descriptions of $\boldsymbol{S}$. bombycis and the many names and synonyms with which these organisms are connected. But an important reason for the mistakes no doubt was the static conception of former bacteriological taxonomy. The research worker in insect microbiology must in future use tests which enable the differentiation of bacteria inside the given group to be made; it is impossible to be satisfied with the generic designation without the corresponding species"determination.

The species Diplococcus bombycis Paillot 1922 is, in my opinion, of doubtful validity, because its description was based on morphology only. The typical diplococcal arrangement of enterococci is quite common and $I$ have also observed it in my strains (Pl. 1, figs. 1, 2). As mentioned before and by other workers (Paillot, 1930a, b, 1941; Steinhaus, 1949; Michailov, 1950; Masera, 1954) streptococci cause a disease of insect gut of chronic character, but under natural conditions some predisposing factors are necessary. It is known that the streptococci are only secondary invaders in virus diseases of insects under natural conditions (Steinhaus, 1949) and my experiments showed that large doses of streptococci, which silkworms would not meet under natural conditions, must be used to produce the disease. The mechanism of infection cannot be fully explained on the basis of my experiments. I suppose the great increase of streptococci in the gut to be connected with some factors such as virus infection or other influence able to stimulate the increase of streptococci in the gut which in silkworms causes a form of dyspepsia. The diverse biochemical activities and the resistance of the streptococci are the reasons for their persisting also in the gut of healthy silkworms. The $\mathrm{pH}$ range for growth streptococci is wide ( $\mathrm{pH} \mathrm{4 \cdot 5-9 \cdot 6)}$ but the $\mathrm{pH}$ values which are necessary for the physiological functioning of insect gut are much more limited. By the multiplication of streptococci the $\mathrm{pH}$ value of the gut is lowered because in the gut contents are many substrates which can be fermented by streptococci. Streptococci as well as staphylococci are found in the gut rather more frequently than other bacteria, a fact which may be explained by the $\mathrm{pH}$ values of the gut. Michailov (1950) found $\mathrm{pH} 9 \cdot 6-10$, but Heimpel (1955, 1956) observed that the values depended on the period of starvation of silkworms and the values he obtained were lower than those of Michailov. My conception is confirmed by the fact that streptococci may be found not only in sick silk worms but also in healthy ones.

Because the pathogenicity of our bombyx strains does not differ essentially from the pathogenicity of the strains of Streptococcus faecalis and S. faecium 
examined, we may state that these bombyx strains are not essentially distinct from the streptococci which are widely distributed in nature. Under the name $S$. bombycis various atypical strains of enterococci may be listed; these are closely related to the species $S$. faecalis and $S$. faecium and, according to Masera's description, also to $S$. faecalis var. zymogenes or $S$. faecalis var. liquefaciens. For this reason I consider the organism named $S$.bombycis, synonyms $S$.bombycis (Pasteur) Flugge, S. bombycis Zopf, S. bombycis Sartirana \& Paccanaro, S. pastorianus Krassilstschik, Micrococcus bombycis Cohn and Diplococcus bombycis Paillot, as insufficiently described and too variable to be regarded as a definite species. Therefore, the name Streptococcus bombycis should be rejected and should be included under nomina rejicienda.

I am indebted to Dr S. T. Cowan, to Academician Ivan Malek and to Dr Jaroslav Weiser for very helpful criticism and comments.

\section{REFERENCES}

Barnes, E. M. (1956). Tetrazolium reduction as a means of differentiating Streptococcus faecalis from Streptococcus faecium. J. gen. Microbiol. 14, 57.

Bergey's Manual of Determinative Bacteriology (1948). 6th edition. Ed. by R. S. Breed, E. G. D. Murray and A. P. Hitchens. Baltimore: Williams and Wilkins Co.

FLüGGe, C. (1886). Die Mikroorganismen, 2nd ed. Leipzig: Kruse.

HeImPel, A. M. (1955). The pH in the gut and blood of the larch sawfly, Pritsiphora erichsonii (HTG), and other insects with reference to the pathogenicity of Bacillus cereus Fr. and Fr. Canad. J. Zool. 33, 99.

Heimpel, A. M. (1956). Further observations on the $\mathrm{pH}$ in the gut and blood of Canadian forest insects. Canad. J. Zool. 34, 210.

Krassilnikov, N. A. (1949). Determination of Bacteria and Actinomycetes. Moscow: Acad. Sci. U.S.S.R. (Translated title.)

Krassilstschik, J. M. (1896). Sur les microbes de la flacherie et de la grasserie de ver à soie. C.R. Acad. Sci., Paris, 123, 428.

LAKE, D. E., Deibel, R. H. \& Niven, C. F., Jun. (1957). The identity of Streptococcus faecium. Bact. Proc. 13, A 17.

Masera, F. (1954). Sul contenuto microbico intestinale del baco da seta e sull'etiologia della flaccidezza. Agricultura Venezol. 1954.

Mrchallov, E. N. (1950). Serriculture. Moscow: Selchozgiz. (Translated title.)

Palllot, A. (1922). Les maladies bactériennes des insectes. Utilisation en agriculture des bactéries entomophytes. Ann. Épiphyt. 8, 95.

Paillot, A. (1928). Les maladies du ver à soie. Lyon: Service photographique de l'Université.

PaIllot, A. $(1930 a)$. Influence des infections microbiennes secondaires sur le développement des ultravirus chez le bombyx du murier. C.R. Soc. Biol., Paris, 104, 585.

Palllot, A. (1930b). Traité des maladies du ver à soie. Paris: G. Doin et Cie.

Paillot, A. (1941). Les travaux de Pasteur sur la flacherie et les théories sur la pathologie du tube intestinal du Bombyx murier. Ann. Epiphyt. 7, 97.

Sartirana, S. \& Paccanaro, A. (1906). Der Streptococcus bombycis in Bezug auf die Aetiologie der Auszehrung und Schlafsucht der Seidenraupen. Z Zbl. Bakt., Abt. I. Orig. 40, 207.

Seelemann, M. (1942). Der Streptococcus bombycis der Seidenraupen-ein 'Enterokokkus' der serologischen Gruppe. Zbl. Bakt. (Abt. II), 105, 173.

Seelemann, M. (1948). Biologie der bei Tieren und Menschen vorkommenden Streptokokken. Nürnberg: Hans Carl. 

Journal of General Microbiology, Vol. 18, No. 3
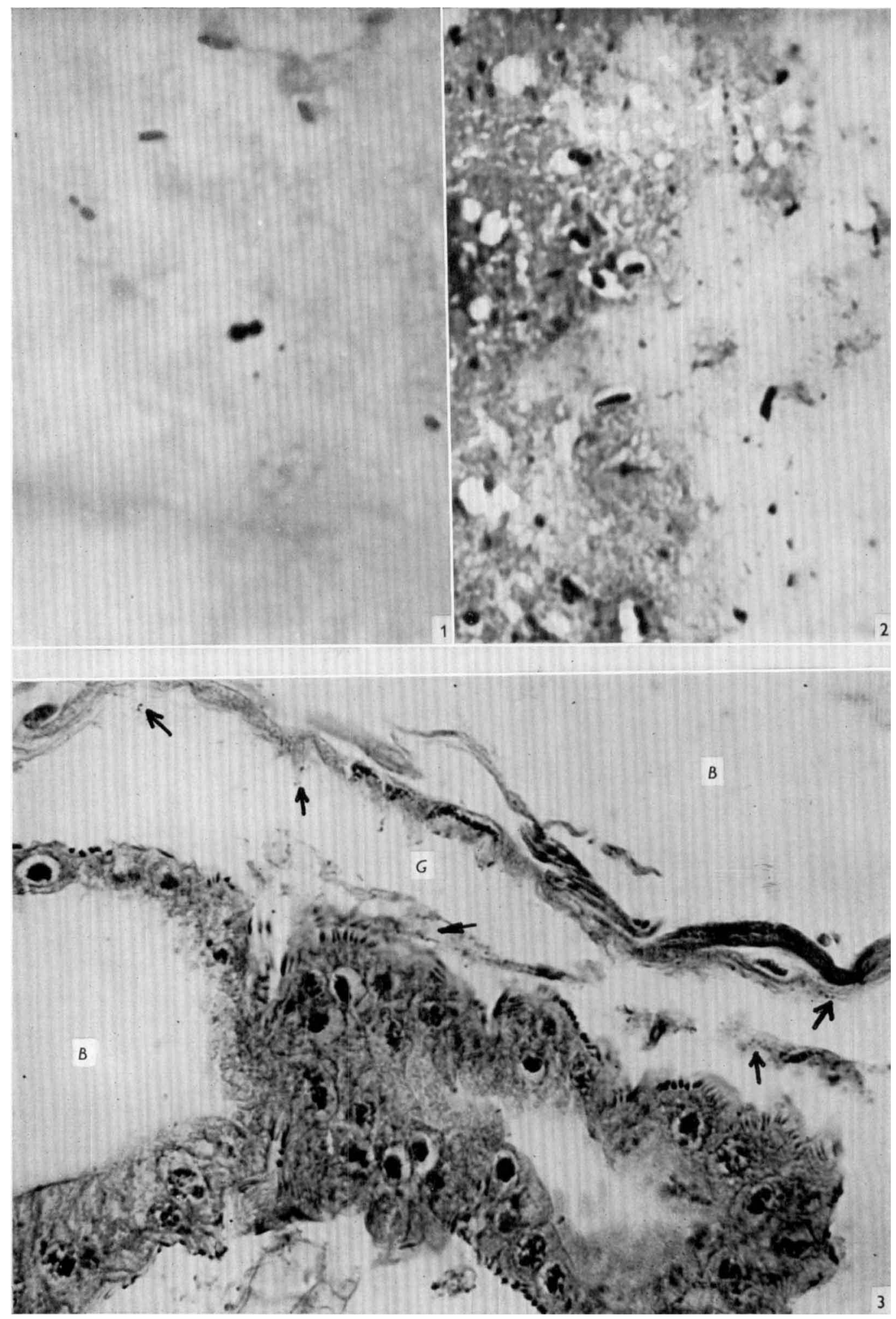

O. Lysenko-Streptococcus bombycts. Plate 1 
Shatтock, P. M. F. (1955). The identification and classification of Streptococcus faecalis and some associated streptococci. Ann. Inst. Pasteur, 7, 95.

Shatтock, P. M. F. \& Hirsch, A. (1947). A liquid medium buffered at pH 9.6 for the differentiation of Streptococcus faecalis from Streptococcus lactis. J. Path. Bact. 59, 495.

Skadhauge, K. (1956). Studies on Enterococci. Copenhagen: Einar Munksgaard.

SNEATH, P. H. A. (1957). Some thoughts on bacterial classification. J. gen. Microbiol. 17, 184.

Steinhaus, E. A. (1949). Principles of Insect Pathology. New York: McGraw-Hill Co.

Weiser, J. \& Lysenko, O. (1956). Silk-worm septicaemia. Csl. Mikrobiol. 1, 216.

Zopf, W. (1884). Die Spaltpilze, 2nd ed. Breslau: Trevendt.

\section{EXPLANATION OF PLATE}

Fig. 1. Streptococcus bombycis strain $\mathrm{Bm} 1 \mathrm{M}$ in the gut of infected silkworm. $\times 4000$.

Fig. 2. 'Streptococcus bombycis' and other bacteria in the haemolymph of a dead silkworm in the stage of a partial decomposition caused by these bacteria. $\times 2500$.

Fig. 3. Cross-section of silkworm gut; the localization of 'Streptococcus bombycis' is shown by arrow heads. $G=$ gut; $B=$ body cavity. $\times 410$.

(Received 6 January 1958) 